\title{
What is the Best Interventional Technique for Lower Extremity Arterial Disease
}

\author{
Mallikarjuna $\mathrm{MRE}^{1^{*}}$ and Ganga $\mathbf{V}^{2}$ \\ ${ }^{1}$ Fellow in Cardiovascular Diseases, University of Arkansas for Medical Sciences, USA \\ ${ }^{2}$ Internal Medicine, St. Vincent Health Care System, USA
}

Corresponding author: Mallikarjuna MRE, Fellow in Cardiovascular Diseases, University of Arkansas for Medical Sciences, USA, Tel: 501-686-7438; E-mail: mmedupuganti@gmail.com

Received date: Aug 01, 2016; Accepted date: Aug 01, 2016; Published date: Aug 07, 2016

Copyright: (c) 2016 Mallikarjuna MRE, et al. This is an open-access article distributed under the terms of the Creative Commons Attribution License, which permits unrestricted use, distribution, and reproduction in any medium, provided the original author and source are credited.

\section{Editorial}

The prevalence of peripheral arterial disease is between $19-30 \%$ [1]. It most commonly involves the superficial femoral artery [2]. Almost 1 in 3 patients more than 70 years of age or patients more than 50 years of age with diabetes or a history of smoking have peripheral vascular disease. However, only $50 \%$ of patients and less than $30 \%$ of physicians treating these patients are aware of this condition. The ratio of asymptomatic to symptomatic PVD is about $3: 1.30 \%$ of asymptomatic patients have total occlusions but are asymptomatic because of presence of excellent collaterals. $25 \%$ of those presenting with intermittent claudication will gradually progress over time. Most deterioration occurs in the first year after diagnosis followed by a slower progression subsequently. An ankle brachial index of less than 0.5 is an important risk factor for disease progression. The amputation rate is about $2 \%$ over 5 years. However, only $50 \%$ of those presenting with critical limb ischemia will be alive at 2 years. Thus the initial presentation is an important consideration in these patients.

The most important conservative management strategies focus on smoking cessation, control of risk factors such as diabetes, antiplatelet therapy and angiotensin receptor blockade. Supervised exercise program is a class 1 recommendation in these patients. Cilostazole also has a role in these patients. Endovascular procedures mentioned below are primarily intended in those with lifestyle limiting symptoms and those that do not respond to conservative treatment.

A number of interventional therapeutic modalities are available for use but it is difficult to compare the effectiveness of the various devices in a systematic fashion. Firstly, the nature of peripheral lesions is varied and the disease can be acute or chronic. Secondly the degree of narrowing can range from total occlusion to varying degrees of stenosis. The length of stenosis can be extremely variable from a few centimetres to several centimetres long, there can be varying degrees of calcification in the vessel and lastly the vessels involved can vary greatly in diameter. It is extremely difficult to construct a systematic study that compares the various interventional devices by controlling for all the aforementioned factors. Furthermore, the definitions of patency and restenosis and the follow up methods can be extremely variable.

Nitinol self-expanding stents are the most commonly used stents in the current day and age. However a number of factors reduce the primary patency rates of stents in peripheral vascular disease, unlike the coronary circulation where the patency rates of stents is excellent. The stents in peripheral arteries are subject to bending and torsional forces, greater lengths of stents are used in the treatment of these lesions and the flow rates in the arteries of the peripheral circulation are lower [3-5]. This has led to a disappointing primary patency rate which ranges from 45 to $90 \%$. Covered stents have an external nitinol stent structure with a polytetrafluoroethylene liner with or without an additional heparin bioactive surface [6-8]. They are thought to prevent intimal hyperplasia and the primary patency rates are about $68 \%$ at 12 months. Several recent developments in the design of drug eluting stents have yielded primary patency rates of $84 \%$ in the treatment of lesions in the superficial femoral artery [9-11].

By eliminating metal struts the use of drug coated balloons reduces the risk of acute thrombosis [12,13]. Bailout stenting is required in $10-12 \%$ of patients often due to the dissection following balloon expansion. The use of cryoplasty balloons involves the application of cold thermal energy to the vessel wall along with the stretch produced by balloon expansion. These reduce the risk if dissection and can be used a strategy for post dilatation following stent implantation. The 12month primary patency rates for this modality of treatment vary from $50 \%$ to $70 \%$. As with balloon dilatation strategies mentioned above the rates of bailout stenting are between $8 \%$ and $28 \%$ [14-16].

Although a number of lesions can be either ballooned or stented a significant number of lesions do not lend themselves to such options and require additional treatment options before they can be made suitable for angioplasty. When used alone, directional atherectomy spares the vessel the trauma from stretch involved in balloon angioplasty $[17,18]$. However adjunctive angioplasty is needed in $60-75 \%$ of patients and bailout stenting is required in $23 \%$. The primary patency rate of this treatment modality is about $63 \%$. Although this rate is comparable to that obtained by balloon angioplasty it is important to note that the lesions for which rotational atherectomy is used are incredibly complex and do not allow for primary angioplasty. Atherectomy devices have the ability to aspirate atherosclerotic debris thus minimizing the risk of peripheral embolization.

Excimer laser ablates restenotic tissue and thus eliminates the risk of peripheral embolization. They also decrease the risk of platelet aggregation [19-21]. It is particularly suited for long complex calcified lesions. However adjunctive angioplasty is required in more than $60 \%$ of cases and bailout stenting is required in up to $25 \%$ of cases. In conclusion, as the lesion complexity increases a variety of treatment options are required in combination and no single treatment modality is adequate. 


\section{References}

1. Hirsch AT, Criqui MH, Treat-Jacobson D, Regensteiner JG, Creager MA, et al. (2001) Peripheral arterial disease detection, aware- ness, and treatment in primary care. JAMA 286: 1317-1324.

2. Kasapis C, Gurm HS (2009) Current approach to the diagnosis and treatment of femoral-popliteal arterial disease. A systematic review. Curr Cardiol Rev 5: 296-311.

3. Bosiers M, Deloose K, Callaert J, Keirse K, Verbist J, et al. (2013) 4-Frenchcompatible endovascular material is safe and effective in the treatment of femoropopliteal occlusive disease: Results of the 4-EVER trial. J Endovasc Ther 20: 746-756.

4. Hong SJ, Ko YG, Kim JS, Hong MK, Jang Y, et al. (2013) Midterm outcomes of subintimal angioplasty supported by primary proximal stenting for chronic total occlusion of the superficial femoral artery. J Endovasc Ther 20: 782-791.

5. Matsumura JS, Yamanouchi D, Goldstein JA, Pollock CW, Bosiers M, et al. (2013) The United States study for evaluating endovascular treatments of lesions in the superficial femoral artery and proximal popliteal by using the protege everflex nitinol stent sys- tem II (DURABILITY II). J Vasc Surg 58: 73-83.

6. Lammer J, Zeller T, Hausegger KA, Schaefer PJ, Gschwendtner M, et al. (2013) Heparin-bonded covered stents versus bare-metal stents for complex femoropopliteal artery lesions: The randomized VIASTAR trial (Viabahn endoprosthesis with PROPATEN bio- active surface [VIA] versus bare nitinol stent in the treatment of long lesions in superficial femoral artery occlusive disease). J Am Coll Cardiol 62: 1320-1327.

7. Geraghty PJ, Mewissen MW, Jaff MR, Ansel GM (2013) Three-year results of the VIBRANT trial of VIABAHN endoprosthesis versus bare nitinol stent implantation for complex superficial femo-ral artery occlusive disease. J Vasc Surg 58: 386-395.

8. Saxon RR, Chervu A, Jones PA, Bajwa TK, Gable DR, et al. (2013) Heparinbonded, expanded polytetrafluoroethylene-lined stent graft in the treatment of femoropopliteal artery disease: 1-Year results of the VIPER (Viabahn endoprosthesis with heparin bio- active surface in the treatment of superficial femoral artery ob- structive disease) trial. J Vasc Interv Radiol 24: 165-173.

9. Dake MD, Scheinert D, Tepe G, Tessarek J, Fanelli F, et al. (2011) Nitinol stents with polymer-free paclitaxel coating for lesions in the superficial femoral and popliteal arteries above the knee: Twelve-month safety and effectiveness results from the Zilver PTX single-arm clinical study. J Endovasc Ther 18: 613- 623.
10. Lammer J, Bosiers M, Zeller T, Schillinger M, Boone E, et al. (2011) First clinical trial of nitinol self-expanding everolimus-eluting stent implantation for peripheral arterial occlusive disease. J Vasc Surg 54: 394-401.

11. Duda SH, Bosiers M, Lammer J, Scheinert D, Zeller T, et al. (2006) Drugeluting and bare nitinol stents for the treatment of athero- sclerotic lesions in the superficial femoral artery: Long-term results from the SIROCCO trial. J Endovasc Ther 13: 701-710.

12. Gandini R, Del Giudice C, Merolla S, Morosetti D, Pampana E, et al. (2013) Treatment of chronic SFA in-stent occlusion with combined laser atherectomy and drug-eluting balloon angioplasty in patients with critical limb ischemia: A single-center, prospective, randomized study. J Endovasc Ther 20: 805-814.

13. Stabile E, Virga V, Salemme L, Cioppa A, Ambrosini V, et al. (2012) Drugeluting balloon for treatment of superficial femoral artery in-stent restenosis. J Am Coll Cardiol 60: 1739-1742.

14. Banerjee S, Brilakis ES, Das TS, Lichtenwalter CS (2009) Treatment of complex superficial femoral artery lesions with PolarCath cryoplasty. Am J Cardiol 104: 447-449.

15. Bakken AM, Saad WE, Davies MG (2008) Cryoballoon angioplasty broadens the role of primary angioplasty and reduces adjuvant stenting in complex superficial femoral artery lesions. J Am Coll Surg 206: 524-532.

16. Samson RH, Showalter DP, Lepore M Jr, Nair DG, Merigliano K (2008) CryoPlasty therapy of the superficial femoral and popliteal arteries: A reappraisal after 44 months' experience. J Vasc Surg 48: 634-637

17. Minko P, Katoh M, Jaeger S, Buecker A (2011) Atherectomy of heavily calcified femoropopliteal stenotic lesions. J Vasc Interv Radiol 22: 995-1000.

18. Trentmann J, Charalambous N, Djawanscher M, Schafer J, Jahnke T (2010) Safety and efficacy of directional atherectomy for the treatment of in-stent restenosis of the femoropopliteal artery. J Cardiovasc Surg (Torino) 51: 551-560.

19. Wissgott C, Kamusella P, Ludtke C, Andresen R (2013) Excimer laser atherectomy after unsuccessful angioplasty of TASC C and D lesions in femoropopliteal arteries. J Cardiovasc Surg (Torino) 54: 359-365.

20. Kim JH, Ahanchi SS, Panneton JM (2012) Identifying the target lesions for 245 laser angioplasty cases and a review of the literature. Vasc Endovascular Surg 46: 640-647.

21. Dave RM, Patlola R, Kollmeyer K, Bunch F, Weinstock BS, et al. (2009) Excimer laser recanalization of femoropopliteal lesions and 1-year patency: Results of the CELLO registry. J Endovasc Ther 16: 665-675. 